\title{
Technology Workshop for a Census of Marine Life
}

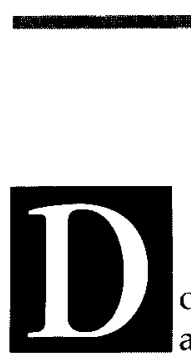

oes a "Census of Marine Life" make sense, and if so, what are the appropriate types of new technologies that one could imagine used to accomplish such a purpose in the near future? After the approximately 18 presentations, there was a great deal of interesting discussion relating to these issues. This document contains the impressions of one of the organizers (J.S. Jaffe) of what transpired and also includes some data and text of examples from some of the newer frontiers that could impact the Census of Marine Life (CoML).

Broadly speaking, the development of new technology can be categorized in many ways. For example, the utilization of optical, acoustic and molecular biological methods can be considered. Alternatively, the animals' habitat can be used as a parameter. Examples are coral reefs, coastal areas, and open ocean. Certainly, each technique has its limitations. In the case of sonar and optics, both attenuation and scattering limit the range and resolution that can be inferred from the data. Although it is certainly true that any device must work within the constraints of the basic physics, the "newer" developments of wide band sonar sources, very sensitive optical cameras, increased signal processing power and molecular biological techniques present new and exciting opportunities which can be used to improve the goal of the census. Although there is much conventional technology and a large body of knowledge relating to its use, the participants at this meeting were very optimistic about the increased knowledge, which could be obtained by using the latest advances in technology.

In the case of acoustics, the presentations centered on the research programs of the individual investigators and the use of acoustics to measure both the abundance and species of fish. Generally speaking, sound waves offer the capability to assess the distribution of fish in moderately large volumes of water $\left(.1 \mathrm{~km}^{3}-100 \mathrm{~km}^{3}\right)$ because of the usable range of the sound, which is typically $100 \mathrm{~s}$ of meters to $10 \mathrm{~s}$ of kilometers for the frequencies of value to the measurement of fish abundance. The most modern sets of acoustical tools employ both multibeam echosounders and wide band sonars which, as demonstrated at the meeting, have the ability to count the numbers of individuals and also to discriminate (to some degree) the type. In a typical survey, the acoustical information, capable of a broad swath, is combined with the results of net trawls for "ground truthing" of the animals. This then permits extrapolation of the trawl results to the larger swath of animals. Several examples of the use of the mathematical and pattern recognition technique of neural nets to discriminate fish species were shown.

An interesting example of a type of long-range detection system is provided by the work of Farmer et al. (1999). Certainly, one of the greatest challenges in determining the distribution of life in the sea is the vastness of the ocean and the relatively short range of our observational tools. Acoustic detection of fish has normally used vertically oriented sonars of one form or another, but such measurements are typically limited to ranges of a few hundred meters. Attempts to extend the reach of fishery sonars have exploited horizontal acoustic propagation. Figure 1 shows the distribution of migrating salmon near the Fraser River detected with a narrow beam $12 \mathrm{kHz}$ sonar towed at $30 \mathrm{~m}$ depth with the acoustic energy directed sideways. Fish are detected to ranges of $7 \mathrm{~km}$ and individual positions derived from the known sonar position and orientation. While the success of this approach is ultimately constrained by propagation and reverberation effects, it is also certain that horizontal imaging opens the door to hugely increased sampling volumes.

Another technique, which employs horizontal propagation using an interesting type of acoustic tomography, was described at the meeting. An experiment which measured absorption losses at the resonance frequencies of sardines were made during Modal Lion, a multidisciplinary experiment, which was designed to isolate absorptivity due to fish with swimbladders from other effects on long range propagation. The results of this experiment suggest the possibility of long term tomographic mapping of fish parameters over large areas using broadband transmission loss measurements. Systematic changes in the resonance frequency 
of dispersed sardines were consistent with concurrent echo sounder observations of the vertical migration of sardines at twilight. Measured resonance frequencies were in good agreement with theoretical computations based on previously measured swim bladder dimensions of sardines (Diachok, 1999).

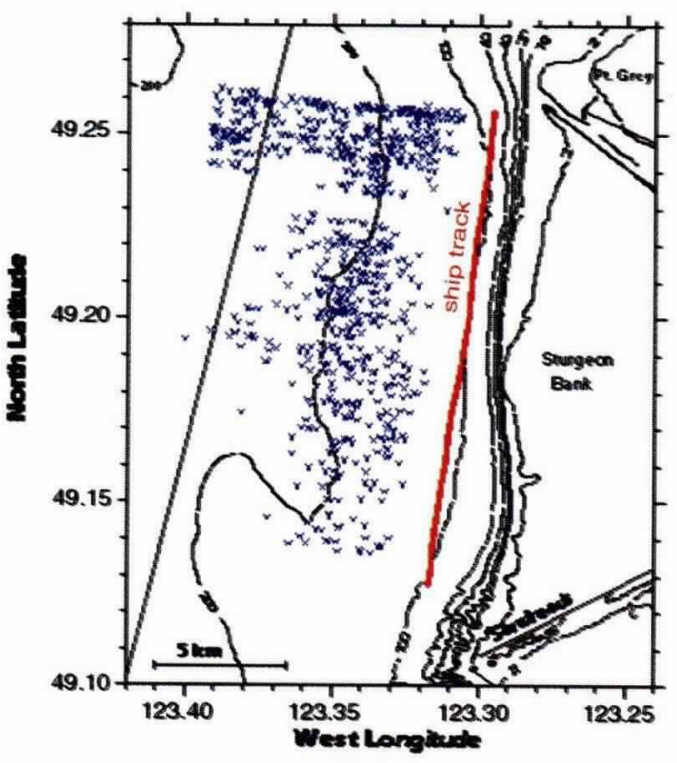

Figure 1: The distribution of migrating salmon near the Fraser River as detected by a side looking sonar towed at $30 \mathrm{~m}$. The sonar can detect individual fish to ranges exceeding $7 \mathrm{~km}$ (adapted from Farmer et al., 1999).

In the use of acoustics to recognize the spatial patterns and abundance of zooplankton and perhaps their interactions with fish, recent progress has made the deployment of moorings of high frequency acoustical systems almost routine. The ability to resolve distributions of small zooplankton and micronekton are now approaching the ten centimeter scale in the vertical, with time resolutions of a minute, from an unattended mooring. Data from one channel $(420 \mathrm{kHz})$ of an inverted echo sounder moored in mid-water where the depth was $22 \mathrm{~m}$ revealed substantial detail about the distribution of plankton biomass above the sensor (Figure 2). The vertical resolution for the system, TAPS ${ }^{\mathrm{TM}}$ (Holliday et al., 1998), operating in its profiling mode, was 12.5 $\mathrm{cm}$. Twenty-four ping averages were collected, distributed via telemetry to a participating ship every minute and to the Internet every hour for several months during the summer of 1998.

Several of the conferees showed examples of the use of optical techniques. In one case, the use of pulsed lasers was demonstrated, and the ability of the method to evaluate the abundance of large schools of fish in surface waters was impressive (Churnside et al., 1997). Advantages of such a method, for oceanography, are that the technique combines the speed of light with the speed of an airplane, in contrast to the case of the sonar which combines the speed of a surface ship with the speed of sound. Of course, the technique is limited to several "optical depths", a function of water clarity. As such, the method holds the most promise for species that are located in the surface waters.

An interesting use of bioluminescence was presented at the meeting. Because bioluminescent plankton and nekton represent such a significant fraction of the marine community, measurements of stimulated bioluminescence can provide a useful tool for remote species identification. In fact, such measurements have been used over a wide range of spatial scales to assess patterns of distribution and abundance. Coarse-scale measurements $(1-100 \mathrm{~km})$ have been made using airborne image-intensifying TV camera systems to detect schools of fish by the bioluminescent plankton (eg. dinoflagellates, radiolaria, ostracods and copepods) which they stimulate as they swim. Fine-scale measurements (1-100 $\mathrm{m})$ of bioluminescence have been made using instruments known as bathyphotometers (Figure 3; Widder et al., 1993). Micro-scale measurements $(1 \mathrm{~cm}$ to $1 \mathrm{~m})$ of biolu

minescence have been made using underwater-intensified video. This technique has been used to identify and map bioluminescent organisms based on the spatial and kinetic patterns of their stimulated bioluminescent displays (Kocak et al., 1999; Widder et al., 1989; Widder et al., 1992; Widder et al., 1993; Widder and Johnsen, 1998; Widder et al., 1999). Since more than $90 \%$ of the individuals and more than $70 \%$ of the species of fish found in midwater collections are bioluminescent (Badcock and Merrett, 1976) a high speed version of this technique could provide a rapid means of assessing fish populations.

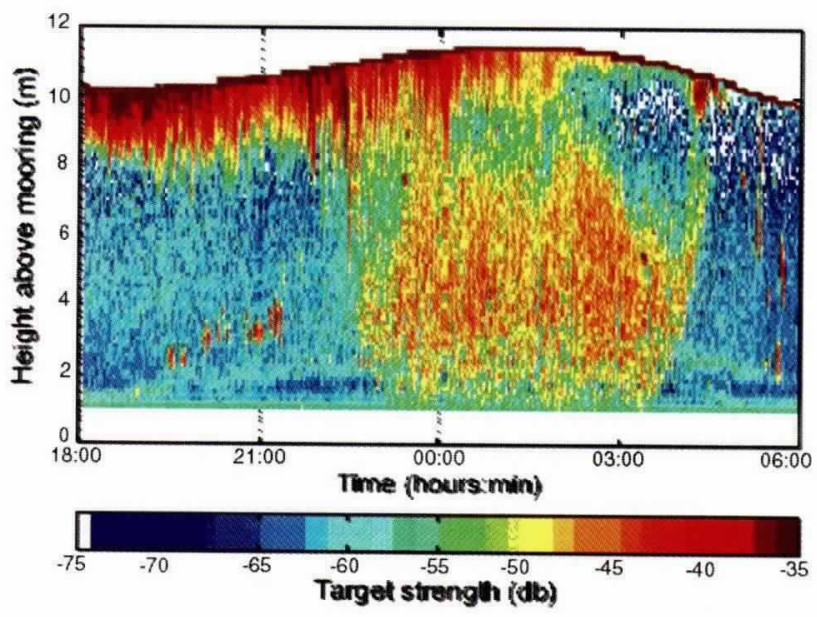

Figure 2: Twelve hours of data from the $420 \mathrm{kHz}$ channel of Marconi's TAPS ${ }^{\mathrm{TM}}$, operating in an inverted echo sounder mode from a mooring nominally at $12 \mathrm{~m}$ depth. The vertical resolution is $12.5 \mathrm{~cm}$ and 24 ping averages were reported at one minute intervals. These data reveal an inverse migration of small zooplankton, possibly the copepod Psuedocalanus.

Finally the combination of acoustics and optics offers new capability for investigating the relationships between zooplankton and phytoplankton and also the use of optics for in-situ target strength identification of animal species and orientation. Figure 4 shows a record 
from a 3-dimensional sonar system, FishTV (Jaffe et al., 1995) which depicts the relationships of a highly acoustically reflective target (fish) and a set of other targets, euphausiids. Both fish and euphausiids were iden-

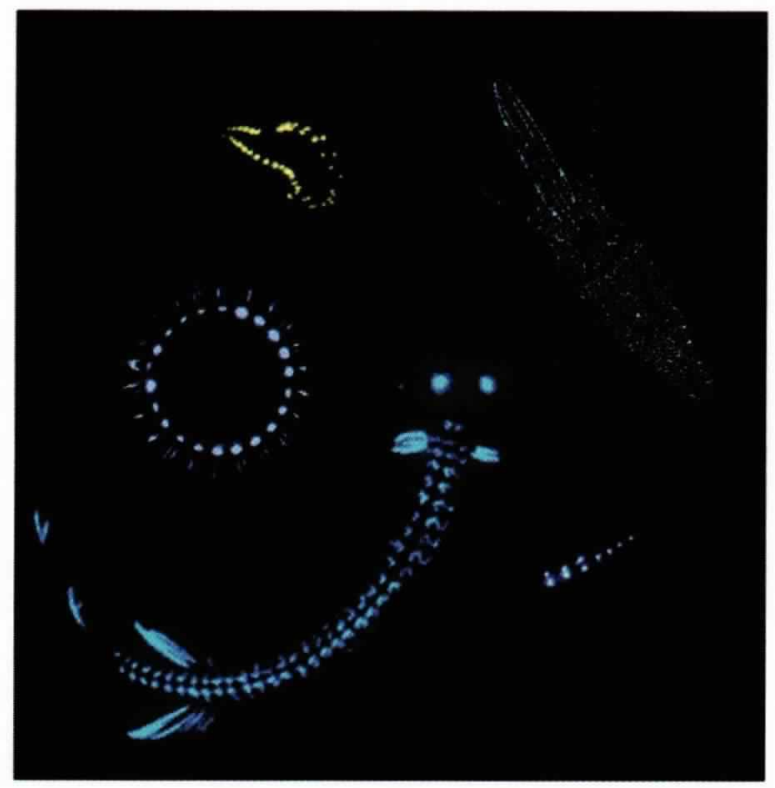

Figure 3: Bioluminescence, which is characteristic of more than $90 \%$ of the animals in the midwater environment, is a species-specific signature with unique spatial, spectral and kinetic properties. With a library of identified signatures it is possible to identify and map the distribution of individual species using computer image-recognition (Widder et al., 1999). Shown here clockwise from top right are the squid, Abralia veranyi, the euphausiid Meganyctiphanes norvegica, the black-dragon fish, Melanostomias bartonbeani, the scyphozoan jellyfish, Atolla wyvillei, and the tomopterid worm, Tomopteris helgolandicus.

tified in-situ with simultaneous optical imaging of the exact targets whose target strength was being estimated (Jaffe et al., 1997). More recent results (Jaffe et al., 1999) demonstrate the advantages of multibeam systems for individual identification in regimes where more conventional systems would need to rely on echo integration methods which are inherently less accurate.

In considering the need for new technology as a consequence of habitat, special problems exist in several areas: coral reefs, the measurement of pelagic species, and in the deep sea. Certainly, these areas are very exciting because they suffer from the greatest technical limitations. As such, an increase in technological capability in these areas could lead to quite startling advances. In the case of coral reefs, most types of traditional sonars do not work because of the acoustic "clutter". New, multibeam, high frequency systems get around these problems to some extent, however, optical methods are still necessary to recognize exact species.

For pelagic oceanic species and other highly mobile groups, telemetric techniques (e.g., sonic transmitters, archival tags) are essential for identification of vertical distribution and horizontal movement patterns. This type of habitat utilization information allows targeting of census effort and development of estimation para- meters which obviate the need to count every single animal in a vast environment. Further, dramatic advances in computer assisted mathematical modeling of the recapture patterns of fish marked with traditional identification tags have breathed new life into this comparatively inexpensive method of estimating the size and distribution of fish populations. Moreover, the evolution of new sensors to allow tagged animals to be more accurately tracked (via inertial sensors or current sensors) could lead to new advances in our ability to monitor these animals.

The deep sea is an area that could yield very interesting data with increased technological help. Conventional scientific trawls are too small to provide an adequate sampling of deep-sea fishes (see Stein, 1985). Large commercial trawls with $>100$ square meter mouth openings are required for censusing deep pelagic and demersal fish populations. Free vehicle pop-up nets (giant conical net - K. Smith, pers. comm) and baited fish traps with gill nets (Smith et al., 1979) are also viable instruments for collecting deep-sea fishes. Remote monitoring of deep-sea fishes using moored acoustical arrays (vertically profiling and side scanning) has revealed very large targets not collected in concurrently set trawls and baited traps at abyssal depths (Smith et al., 1989; Smith et al., 1992). Acoustic tagging of scavenging fishes on the sea floor has been successful in monitoring population dynamics of selected species (Priede and Smith, 1986). This area has been somewhat inaccessible, primarily due to the cost and difficulty of preparing and deploying sensor packages to these depths.

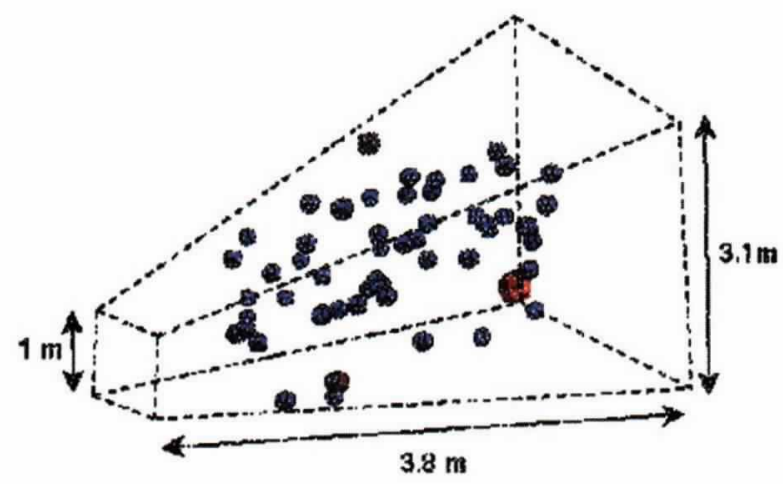

Figure 4: The results of analysis of an image taken by the multibeam sonar system FishTV. The figure depicts many smaller targets (euphausiids) surrounded by a larger target (fish). Color is proportional to target strength and varied from $-58 \mathrm{~dB}$ (fish) to $-95 \mathrm{~dB}$, the smallest euphausiid. Target strengths were collected in-situ with optical confirmation of the species.

Although the meeting discussions were not concerned too much with sampling strategies, it is clear that any full-fledged effort to census marine animals would necessarily need to examine these issues. The use of "ships of opportunity" seemed exciting, especially for areas such as the South Pacific and the west part of the Indian Ocean, widely regarded as extremely 
undersampled. One suggestion was to install an automatic quantitative echo sounder onboard fisheries boats, merchant ships, passenger vessels, ferries, or research vessels, so that we could gather continuous data for a broad sea area and analyze the data by standardized methods, resulting in a global census of fish. In pursuit of this goal, it would be better to develop an automatic, robust, simple, and standardized quantitative echo sounder. The automatic sounder should have the following four properties: (1) automatic (no operator), (2) robust (get reliable data under almost all conditions, no malfunction), (3) simple (only important components or method, cheap) and (4) standardized (standardized specifications and data format).

Other methods which did receive some degree of consensus considered the installation of "toll gates". That is, sets of moorings which would be placed in strategic locations where it was known that a great many animals can be found in their migratory routes. Another area is the use of satellite imagery as a method for determining areas of interest. Certainly fisherman are using these techniques more and more to identify potential areas for large schools of open-water fish.

Finally, the answers to the basic questions, is a census of marine life interesting from a scientific point of view and, are the technological opportunities to make such a census feasible worth pursuing, are yes, and yes. Certainly, all of the participants at the meeting, including the author of this document, went away with the impression that there was much to learn that is new and that advances in technology make such an effort even more of a feasible endeavor than ever before.

\section{Acknowledgements:}

Contributions to this article from David Farmer, Ken Smith, Orest Diachok, Eddie Widder, M. Furusawa, D. Van Holliday and Kim Holland after the workshop are gratefully acknowledged.

\section{REFERENCES:}

Badcock, J.R. and N.R. Merrett, 1976: Vertical distribution of midwater fishes. Prog. Oceanogr., 7, 3-58.

Churnside, J.H., J.J. Wilson, and V.V. Tatarskii, 1997: Lidar profiles of fish schools. Applied Optics, 36, 24, 6011-6020.

Diachok, O., 1999: Effects of absorptivity due to fish on transmission loss in shallow water. J. Acous. Soc. Am., 5(4), 2107-2128.

Farmer, D.M., M.V. Trevorrow and B. Pedersen, 1999: Intermediate range fish detection with a $12 \mathrm{kHz}$ sidescan Sonar. J. Acoust. Soc. Am, in press.

Holliday, D.V., R.E. Pieper, C.F. Greenlaw and J.K. Dawson, 1998: Acoustical sensing of small-scale vertical structures in zooplankton assemblages. Oceanography, 11(1), 18-23.

Jaffe, J.S., E. Reuss, D. McGehee and G. Chandran, 1995: FTV, a sonar for tracking macrozooplankton in three- dimensions. Deep Sea Research, 42(8), 1495-1512.

Jaffe, J.S., M.D. Ohman and A. DeRobertis, 1997: Oasis in the sea: Measurement of the acoustic reflectivity of zooplankton with concurrent optical imaging. Deep Sea Research, 45(7), 1239-1243,1245-1253.

Jaffe, J.S., A. DeRobertis and M.D. Ohman, 1999: Sonar estimates of daytime activity levels of Euphausia pacifica in Saanich Inlet. Can. J. of Fisheries and Aquatic Sciences, in press.

Kocak, D.M., N.D.V. Lobo and E.A. Widder, 1999: Computer vision techniques for quantifying, tracking and identifying bioluminescent plankton. IEEE $/$. Oceanic Engineering, 24(1), 81-95.

Priede, I.G. and K.L. Smith, Jr., 1986: Behaviour of the Abyssal Grenadier, Coryphaenoides yaquinae, monitored using ingestible acoustic transmitters in the Pacific Ocean. J. Fish. Biol., 29(Suppl.A), 199-206.

Smith, K.L., Jr., G.A. White, M.B. Laver, R.R. McConnaughey and J.P. Meador, 1979: Free vehicle capture of abyssopelagic animals. Deep-Sea Res., 26A, 57-64.

Smith, K.L., Jr., D. Alexandrou and J.L. Edelman, 1989: Acoustic detection and tracking of abyssopelagic animals: A description of an autonomous split-beam acoustic array. Deep-Sea Res., 36, 1427-1441.

Smith, K.L., Jr., R.S. Kaufmann, J.L. Edelman and R.J. Baldwin, 1992: Abyssopelagic fauna in the central north pacific: Comparison of acoustic detection and trawl and baited trap collections to $5800 \mathrm{~m}$. Deep-Sea Res., 39, 659-685.

Stein, D.L., 1985: Towing large nets by single warp at abyssal depths: Methods and biological results. DeepSea Res., 32A, 183-200.

Widder, E.A., S.A. Bernstein, D.F. Bracher, J.F. Case, K.R. Reisenbichler, J.J. Torres and B.H. Robison, 1989: Bioluminescence in Monterey submarine canyon: Image analysis of video recordings from a midwater submersible. Mar.Biol., 100, 541-551.

Widder, E.A., C.H. Greene and M.J. Youngbluth, 1992: Bioluminescence of sound-scattering layers in the Gulf of Maine. J.Plank.Res., 14, 1607-1624.

Widder, E.A., J.F. Case, S.A. Bernstein, S. Macintyre, M.R. Lowenstine, M.R. Bowlby and D.P. Cook, 1993: New large volume bioluminescence bathyphotometer with defined turbulence excitation. Decp-Sea Res., $40,607-627$.

Widder, E.A. and S. Johnsen, 1998: Optical imaging, identification and $3 \mathrm{D}$ analysis of spatial distribution patterns of bioluminescent plankton. SPIE Ocean Optics XIV.

Widder, E.A., S. Johnsen, S.A. Bernstein, J.F. Case and D.J. Neilson, 1999: Thin layers of bioluminescent copepods found at density discontinuities in the water column. Mar. Biol., in press. 